\title{
Determinants OF AdOPTING A ZERo WASTE CONSUMER LIFESTYLE
}

\author{
Zsuzsa SĂPLĂCAN ${ }^{1}$, Brigitta MÁRTON ${ }^{2}$ \\ ${ }^{1}$ Babeş-Bolyai University, Faculty of Economics and Business Administration, \\ RO-400591 Cluj-Napoca, Teodor Mihali Str. 58-60. \\ ${ }^{2}$ Moholy-Nagy University of Art and Design, H-1121 Budapest, Zugligeti u. 9-25.
}

\begin{abstract}
As of 2019, Euromonitor International predicted that one of the most emerging consumer trends would be the aspiration and acting for a plastic-free world. The concept of Zero waste has been widely discussed in production technology and waste management literature, however, in recent years environmentally conscious consumers also decided to get more involved in concrete - and sometimes radical - waste reduction actions, even lifestyle changes. These initiatives were also supported by the authorities by banning certain single-use plastic items in the European Union by 2021. Media and social media personalities also have thematized the waste pollution problem and have brought closer to the population the principles of zero waste lifestyle. While the environmentally conscious consumer behavior has been researched widely before, the diffusion of zero waste principles at household level has not been in the researchers' focus. The present study aims to conceptualize and then identify the dimensions and the determinants of a zero waste consumer lifestyle. Questionnaire-based research has been delivered on a sample of 378 people active in zero waste social media groups in Hungary. Our results reveal that the waste reduction initiatives are the most important components of the zero waste behavior; however, dimensions of reusing and recycling products, packages or waste are also identified. The zero waste consumer is driven by altruistic motivations, is nonconformist, guided by his own values and convictions, shows positive attitude towards zero wasters' efforts, follows social media influencers' videos in zero waste matters and is active in social media groups.
\end{abstract}

Keywords: zero waste, consumer lifestyle, TRA, 3R, social media

\section{INTRODUCTION}

On a daily basis we receive shocking information and pictures on the damages caused by unstoppable plastic pollution and other waste issues. Solid waste has become one of the largest global environmental issues (Minelgaite and Liobikiene, 2019). The European Commission proposed a circular economy vision and the introduction of a zero waste strategy (European Commission, 2014), in order to increase the more efficient use of the resources, to reduce the waste generation and leakage and to promote an economically and environmentally sustainable growth. A zero waste strategy provides benefits to the community, changes the people's lifestyle about consumption patterns and their attitudes towards waste disposal, ensures economic and financial benefits, environmental benefits and also specific benefits for industries and their stakeholders (Pietzsch et al., 2017). 
The waste generated during the whole value chain has become a global and collective issue. Some environmentally sensitive consumers feel that they would take control, and initiate a bottom-up changing. For the year 2019, Euromonitor International predicted that one of the most sharply emerging consumer trends would be the aspiration and acting for a plastic-free world (Angus and Westbrook, 2019). Zero waste is becoming a trend and creating a buzz across Europe and beyond (Zero Waste Europe, 2019). Social media can amplify this buzz and helps to propagate the movement.

The zero waste concept traditionally was developed in production and supply chain management on the company level, and in the waste management on city or community level (Lehmann, 2011b). It is a holistic concept of the waste handling problem in the twenty-first century (Zaman, 2015). However, several studies on the zero waste principles neglect the demand side of the waste problem and the willingness and forms of the consumers' participation in zero waste value chains (Kirchberr et al., 2017). The zero waste lifestyle re-frames the practice of shopping, consumption and disposal of the waste. For example, to perform package-free shopping, consumers have to learn new competences and knowledge, need to develop own buying and storage infrastructure (Fuentes et al., 2019). Even so, recently the consumer awareness towards environmentally friendly consumer behavior has been emerging more than ever. The zero waste consumer movement is at the intersection of the two different topics: the zero waste management practices developed on the organization level and the environmentally friendly behavior on the individual or household level.

While the environmentally conscious consumer behavior has been researched widely before in literature, the diffusion of zero waste principles on individual and household level has not been in the researchers' focus. Therefore, the aim of this study is to conceptualize the zero waste lifestyle, to identify its dimensions, and to explore the determinants of a zero waste lifestyle adoption.

\section{Conceptualization zero waste consumer lifestyle}

Zero waste $(\mathrm{ZW})$ was one of the most studied topics in the past decade in waste management (Zaman, 2016). Being at the intersection of several disciplines, it is also a controversial subject. The term "zero waste" was first used by Dr. Paul Palmer in 1973 for recovering resources from chemicals (Zaman, 2015). According to the most recent definition of the ZW, formulated by the Zero Waste International Alliance, ZW is "The conservation of all resources by means of responsible production, consumption, reuse, and recovery of products, packaging, and materials without burning and with no discharges to land, water, or air that threaten the environment or human health." (ZWIA, 2018). This definition is more operational and task-oriented, in comparison with the older one, which defined ZW as an "ethical, economical, and efficient and visionary [goal], to guide people in changing their lifestyles and practices to emulate sustainable natural cycle, where all discarded materials are designed to become resources for others to use [...]" (ZWLA, 2018).

In the ZW concept, the waste is seen as a resource created at the different stages of a product's value chain, including production and consumption (Zaman, 2016) that 
should be used again, instead of incinerating or disposed of in a landfill. In this chain the waste should be reintroduced in the production process through reuse, recycle, reassemble, resell, redesign or reprocess. Thus, the ZW principles contribute to the circular economy (Lehmann, 2011a; Zaman, 2016; Pietzsch et al., 2017). Kirchherr et al. (2017) provide a definition for the circular economy similar to the ZW principles. I.e. the circular economy, as an economic system that replaces the 'end-of-life' concept with reducing, reusing, recycling and recovering materials in production, distribution and consumption phase of their life cycle (Kirchherr et al., 2017).

In a circular economy, waste reducing, reusing, and recycling (3R waste hierarchy) behaviors play central roles, $3 \mathrm{R}$ theory being a widely accepted tool of waste management (Ma et al., 2017). The waste hierarchy shows how waste avoidance is preferred in the first place, above reuse and recycling (Lebmann, 2011a). On the other hand, this waste hierarchy on the household level contributes towards achieving sustainable consumption (Pandley et al., 2017).

The Reduction principle refers to minimizing the amount of waste through the improvement of efficiency in production and reducing consumption. This could be realized e.g. using more efficient technologies, less packaging or a simpler lifestyle. The Reuse principle stands for using again a product or a component/material of the product according to the original purpose (European Parliament 2008). On the consumer side this consists of choosing reused and remanufactured products, preferring durable products (Prendeville et al., 2014). The Recycle principle refers to the recovery operation when waste is reprocessed into products or materials, it could happen for the original or other purposes. It includes the reprocessing of organic materials, too (European Parliament, 2008). Minelgaite and Liobikiene (2019) in their study also use the $3 \mathrm{R}$ principles as the dimensions of waste management.

According to Kirchberr et al. (2017), the circular economy strategy involves micro level agents, such as companies or consumers, meso level economic and social ecosystems and macro level entities such as cities, geographic regions, countries. The emergence of the circular economy drives the development of new business models and responsible consumer behavior patterns (Kirchherr et al., 2017).

The concept of ZW is continuing to be adopted by individuals, families on the household level (Zaman, 2016; Hannon and Zaman, 2018). While the value chain ends at the consumer, the consumer should be included in the waste management strategies, and some of the tasks should be delegated to the consumers. Zaman (2015) put the proposed waste avoidance strategy into consumers' responsibilities, which means avoiding over-consumption and promoting sustainable consumption. The Planet Aid (2016) organization defines the ZW as "a lifestyle where people aim to eliminate their trash output completely. This means no plastic, no wrappers, no garbage".

The consumer's involvement in several ecologically friendly behavior in every stage of the consumption process became crucial in solving several environmental problems (Onel and Mukherjee, 2017). The 3R strategy has been developed at a meso or macro level, but is there a possibility to apply at the household level? The environmentally conscious consumer behavior and consumer profile have been researched for decades (Webster, 1975). For example, Webster (1975) found that recycling behavior is part of the socially conscious behavior. Zimmer et al. (1994) 
identified seven dimensions of environmental concern, including concern for waste (waste control, landfills, recycling, etc.), concern for wildlife (wildlife, habitat protection, deforestation, etc.), concern for the biosphere (biosphere protection, ozone depletion, etc.), concern for popular issues (labeling, environmental education, etc.), concern for health (water, air pollution, etc.), energy awareness (clean energy, energy conservation, etc.), and concern for environmental technology (biotech, composting etc.). Robert and Bacon (1997) identified six factors of the environmentally conscious consumer behavior, such as products from recycled paper, saving (fossil) energy, waste recycling issues, eco-conscious decision making, increasing energy efficiency and reducing electricity consumption. Li et al. (2019) also identified a series of operationalized pro-environmental behavior, such as recycling waste, other waste management issues, energy consumption, transport usage, purchasing green products or purchasing eco-friendly appliances (Li et al., 2019).

Besides the more holistic approaches of environmentally conscious consumer behavior studies, several specific topics that involve the consumer have been investigated in the consumer literature. In trying to identify the $3 \mathrm{R}$ model components in case of the environmentally conscious consumer behavior, it can be concluded that Reducing and Reusing behavior appear implicitly in the waste concerns, while the Recycling gains special attention and place in consumers' environmental concerns.

As part of the environmentally conscious consumer behavior, the Recycling behavior of consumers and its antecedents have been widely researched in consumer literature (Davies et al., 2002; Izagirre-Olaizola et al., 2015; Kirchherr et al., 2017; Onel and Mukherjee, 2017; Pandley et al., 2017; Minelgaite and Liobikiene, 2019;). Recently, some studies have also mentioned reducing behavior issues (Graham-Rowe et al., 2014; Mintr et al., 2019). Reusing aspects, such as second-hand shopping, donation or resell appears in several fashion and clothing related researches (Weber et al., 2016).

Thus, we consider that ZW lifestyle is a subset of environmentally friendly, or green consumer behavior, which manifests in a concrete and much-focused strategies and actions undertaken by consumers regarding waste management on the household level. It is focused on reducing solid waste, reusing the discarded products and recycling the incidentally created waste at the end of the product's life cycle. It can be applied at any segment of the life, regarding food, clothing, electronic products, etc. and all related services (food service, cleaning, etc.) or in any steps of the purchasing and consuming journey. In order to identify the components of the ZW lifestyle, we formulate the following research question:

RQ1 - Which are the dimensions of the zero waste consumer lifestyle?

\section{Determinants of the Zero waste consumer lifestyle}

The determinants of the pro-environmental consumer behavior have been researched widely before. While the environmentally friendly behavior is a wider concept, encompassing several aspects of the reduction of pollution, the ZW is focused mainly on solid waste issues on household level regarding food, cosmetics, hygienic and household products and textile waste management. The majority of 
the studies related to one or more aspects of the ZW investigate the recycling behavior (Davies et al., 2002; Khan et al., 2019), the other dimensions of the 3R model are rarely examined (Mintz, et al., 2019).

A lot of the environmentally conscious consumer studies are developed either on the Theory of Reasoned Action (TRA) (Fishbein and Ajzen, 1975) or on the Theory of Planned Behavior (TPB) by Ajzen (1991) (Liobikiene et al., 2016; Khan et al., 2019; Li et al., 2019). According to these theories, the attitude towards the action and the social pressure are significant predictors of the intention to act. In addition to these two determinants, the TPB also includes the perceived behavioral control as an important predictor of the behavioral intention (Ajzen, 1991).

The attitude towards the action is in the center of several environmentally friendly behavior studies. The attitude reflects how favorable it is perceived by the consumer to perform the behavior (Ajzen, 1991). In several environmentally conscious behavior studies it has been found that a more positive attitude results in higher likelihood to be involved in a recycling action (Davies et al., 2002; Ma et al., 2017).

While the subjective norm is one of the major predictors of the intention to behave in a certain way, and indirectly of the actual behavior, the results of the studies are divergent. Subjective norm refers to consumers' perceived social pressure to whether to perform or not the behavior ( $L i$ et al., 2019). While some authors found that subjective norm is an important predictor of the recycling behavior (Khan et al., 2019) or on the purchasing green products (Liobikiene et al., 2016), others have not identified its significant impact on the recycling behavior (Davies et al., 2002; Ma et al., 2017). In an international setting Mintz. et al. (2019) found that social norms predict in Germany the waste minimization and recycling in every condition but in Israel social norm was significant in waste minimization and recycling only when it was easy to do it.

When it comes to the ZW consumer behavior, it is important to define who are the reference persons of the subjective norm: the non-ZW individuals or the ZW individuals, whereas the plastic-free lifestyle ideas are considered as niche behavior, yet (Angus and Westbrook, 2019). Therefore, in completion of the subjective norm, meaning following others, the personal norm could also be investigated as a possible predictor of the ZW lifestyle adoption. Personal norm is an important individual difference that reflects the sense of personal obligation towards self-standards (White et al., 2019). It has been found that a stronger personal norm increases the attention to the environmental friendliness of packaging during the buying decision process (Thogersen, 1999).

Motivations of waste management issues is a quite complex system (Moisander, 2007). Li et al. (2019) mark motivation as one of the factors which influences the pro-environmental behavior. Exploring the motivations behind waste reduction is an essential step to designing effective solutions for the waste problem (GrahamRowe et al., 2014). The bipolar interpretation of the motivation in an environmentally conscious context is a common approach, implying individual vs. collective motivation (Moisander, 2007) or altruistic vs. egoistic motivation (McDougle et al., 2011). Altruistic motivations are a significant predictor of engagement in recycling (Izagirre-Olaizola et al., 2015). On the other hand, egoistic motivation has a negative impact on environmental concern (Onel and Mukherjee, 2017). Egoistic 
motivation means self-concern, consumer calculating the personal cost and the benefit of the action.

Conscious consumers are influential, and they are more likely to spread information to others (Angus and Westbrook, 2019). Social media and online influencers could be seen as a booster of the ZW principles on the household level. Bedard and Tolmie (2018) found a positive relationship between levels of social media usage and levels of green purchase intentions. They also found that online interpersonal influence has an impact on green purchase intentions. Instagram accounts focusing on zero waste are important sources of inspiration and show that pro-environmental principles can be incorporated into our lifestyle. This motivates the social media consumers to follow the zero waste influencers' example (Fuentes et al., 2019).

The research sought to examine the influence of the classical TRA variables on the ZW behavior extended with motivational factors and the impact of social media usage. The conceptual model behind the research design is represented in Figure 1. In the model, in the case of the Reuse dimension, the waste is enclosed in quotation marks because, according to the circular economy concept, the reusable waste is not waste anymore, but it is a valuable input for other activities. We formulate the following research question in order to investigate the antecedents of the ZW lifestyle:

RQ2 - Which are the determinants of the zero waste lifestyle adoption on the consumer level?

\section{Figure 1}

\section{Conceptual framework}

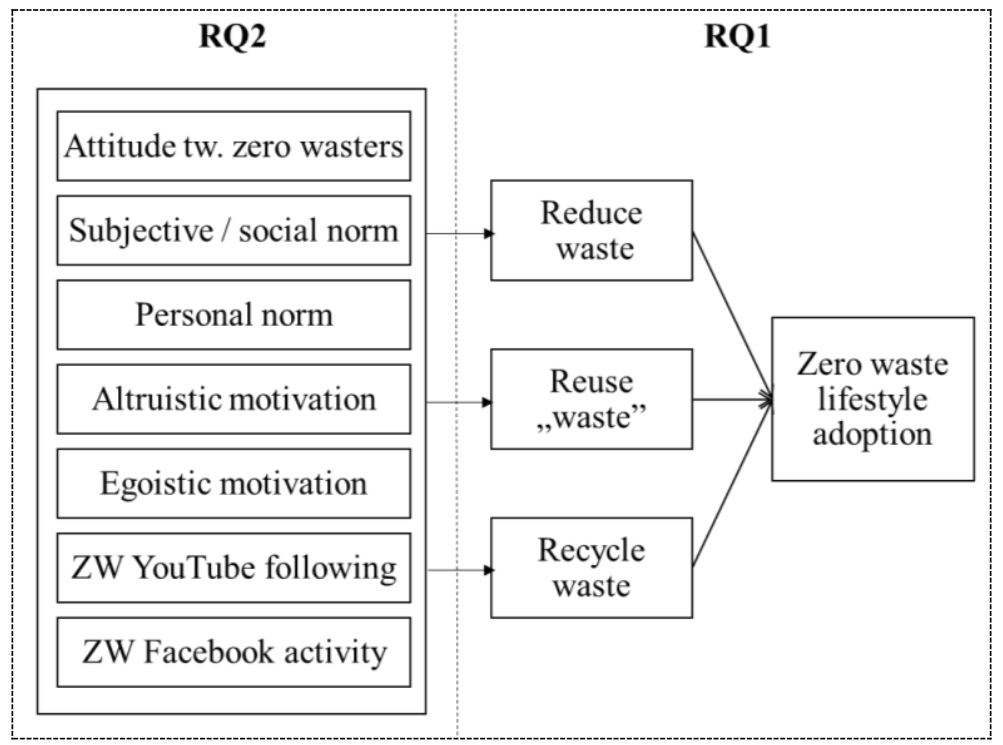

\section{MATERIALS AND METHODS}

The data collection was undertaken in June-August 2019 through an online questionnaire. The distribution channels of the questionnaire were four different 
Facebook groups for zero wasters in Hungary. We used these channels because of the easiness to reach those who consume social media content in this topic and can express their opinion on this issue. On the other hand, these groups bring together a huge number of green consumers (one of the groups has 24000 members, the others have between $900-3,000$ members). In addition to this, social media is the main channel for zero wasters to share information about this lifestyle.

Table 1

\section{Sample's characteristics}

\begin{tabular}{|l|l|c|c|}
\hline Variable & Category & Frequency & Percent \\
\hline \multirow{4}{*}{ Gender } & female & 333 & $88 \%$ \\
\cline { 2 - 4 } & male & 43 & $11 \%$ \\
\cline { 2 - 4 } & no answ. & 2 & $1 \%$ \\
\hline \multirow{4}{*}{ Age } & $18-25$ years & 148 & $39 \%$ \\
\cline { 2 - 4 } & $26-35$ years & 128 & $34 \%$ \\
\cline { 2 - 4 } & $36-45$ years & 70 & $19 \%$ \\
\cline { 2 - 4 } & above 46 years & 32 & $8 \%$ \\
\hline \multirow{4}{*}{ Education } & capital & 106 & $28 \%$ \\
\cline { 2 - 4 } & other city & 204 & $54 \%$ \\
\cline { 2 - 4 } & rural & 68 & $18 \%$ \\
\cline { 2 - 4 } & General school & 4 & $1 \%$ \\
\cline { 2 - 4 } & High school & 50 & $13 \%$ \\
\cline { 2 - 4 } & Undergraduate student & 101 & $27 \%$ \\
\hline \multirow{5}{*}{ status } & University/college graduate & 223 & $59 \%$ \\
\cline { 2 - 4 } & Married with child & 133 & $35 \%$ \\
\cline { 2 - 4 } & Couple without child & 131 & $35 \%$ \\
\cline { 2 - 4 } & Single & 30 & $21 \%$ \\
\cline { 2 - 4 } & Married without child & 34 & $9 \%$ \\
\cline { 2 - 4 } & Total & & $100 \%$ \\
\hline \multirow{5}{*}{} & & 378 & \\
\hline
\end{tabular}

We received 378 responses, more than $88 \%$ of the respondents were female, $54 \%$ of them live in cities outside the capital, and $73 \%$ of them are aged between 18-35 years (Table 1). Women are overrepresented in this sample, but this shows that the zero waste thinking influences mostly the household choices which are mostly headed by women (Straughan and Roberts, 1999), and also they are more open to this lifestyle (Laroche et al., 2001).

The adoption of the ZW lifestyle (ZW life adopt) variable was measured by a single-item Likert-scale, the Reducing, Reusing and Recycling dimensions were measured by 25 items Likert scales, derived from literature (Stranghan and Roberts, 1999) and from ZW blog and video recommendations. The altruistic (ALTRmot) and egoistic (EGOmot) motivation also were measured by 8 item Likert scales. The 
subjective norm $(\mathrm{SN})$, the personal norms (PN) and the attitude towards zero wasters (ZWatt) were measured by two-item Likert scales each, while the social media activity including watching ZW YouTubers (ZW YT watching) and being active on ZW Facebook groups (ZW FB activity) were measured by 3-point scales on frequency (never - often).

The data were analyzed with IBM SPSS - 23 statistic program. For the multiitem construct such as the Reducing, Reusing and Recycling dimensions, respectively for the altruistic and egoistic motivation Exploratory Factor Analyses were performed using the Principal Component Analysis method, with Varimax rotation. Factors with eigenvalue above 1 were extracted. After that, for each factor created, the arithmetic mean of the factor items was calculated. The central result of the factor analysis is presented in the result section. Then a Multiple Linear Regression procedure was applied, first for each three ZW dimension, as dependent variables, then for the general ZW lifestyle adoption as dependent, and Reducing, Reusing and Recycling as independent variables.

\section{RESULTS AND DISCUSSION}

According to the factor analysis, the original list of the $25 \mathrm{ZW}$ behavior items was reduced to 16 items. The eliminated items were not representative for our sample, such as bamboo toothbrush or textile napkin usage, and they got very low general scores, or they did not correlate well with the other factor items. The exploratory factor analysis then returned three factors which explain $52.8 \%$ of the total variance. All the factor loadings were above the 0.5 value (Table 2), which is acceptable for this sample size (Sajtos and Mitev, 2007).

\section{Table 2}

\section{ZW lifestyle dimensions factors}

\begin{tabular}{|l|l|c|c|c|c|}
\hline Dimension & \multicolumn{1}{|c|}{ Item } & Mean & $\begin{array}{c}\text { Stnd. } \\
\text { Dev. }\end{array}$ & $\begin{array}{c}\text { Factor } \\
\text { Loading* }\end{array}$ & $\begin{array}{c}\text { Cronbach' } \\
\text { s alpha }\end{array}$ \\
\hline \multirow{5}{*}{ Reduce } & Own shopping bag & 4.53 & 0.87 & 0.712 & \\
\cline { 2 - 5 } & $\begin{array}{l}\text { Own textile bag for } \\
\text { vegetables }\end{array}$ & 3.67 & 1.49 & 0.668 & \\
\cline { 2 - 5 } & Own water bottle & 4.29 & 1.10 & 0.655 & \multirow{2}{*}{0.856} \\
\cline { 2 - 5 } & No straw & 4.06 & 1.31 & 0.639 & \\
\cline { 2 - 5 } & Avoid plastic & 3.95 & 1.06 & 0.631 & \\
\cline { 2 - 5 } & Textile bag patisseries & 3.71 & 1.34 & 0.619 & \\
\cline { 2 - 5 } & Seek package-free & 3.79 & 1.16 & 0.605 & \\
\cline { 2 - 5 } & No printing & 3.55 & 1.42 & 0.583 & \\
\cline { 2 - 5 } & No disposable tools & 3.89 & 1.08 & 0.547 & \\
\cline { 2 - 5 } & Own food box & 2.99 & 1.47 & 0.532 & \\
\hline
\end{tabular}

Continued on the next page 
Continued from the page before

\begin{tabular}{|c|c|c|c|c|c|}
\hline \multirow{4}{*}{ Reuse } & $\begin{array}{l}\text { Second-hand or sustainable } \\
\text { clothes }\end{array}$ & 2.97 & 1.30 & 0.844 & \multirow{4}{*}{0.722} \\
\hline & Second-hand products & 3.19 & 1.27 & 0.769 & \\
\hline & Natural fiber clothes & 3.56 & 1.19 & 0.572 & \\
\hline & $\begin{array}{l}\text { Products from recycled } \\
\text { material }\end{array}$ & 3.17 & 1.26 & 0.514 & \\
\hline \multirow{2}{*}{ Recycle } & Compost/Rot & 2.84 & 1.73 & 0.812 & \multirow{2}{*}{0.504} \\
\hline & Collect selective garbage & 4.25 & 1.20 & 0.586 & \\
\hline
\end{tabular}

The analyses returned a KMO $0.879>0.8$ which is a very good fit (Sajtos and Mitev, 2007). The first factor was identified as the Reducing, the second as the Reusing and the third one as Recycling factor. Additional Cronbach's Alpha has been calculated in order to measure the internal reliability of the dimension scales. For the Reduce and Reuse dimension the $\alpha>0.7$, and can be considered (V aske et al., 2017). For the Recycle dimension, we have a Cronbach alpha of 0.504, which might be problematic. However, it is known that there is not a consensus on the acceptable threshold of the Cronbach's Alpha (Taber, 2018). So, we would accept this dimension, as the factor analysis returned this factor, and the correlation of the Composting item is the highest with the Selective garbage collecting item. Nevertheless, further research can be undertaken to refine the scale.

Overall, the usage of own shopping bag (4.53), the usage of own water bottle (4.29) and the selective garbage collection (4.25) are the more practiced waste management consumer activities. Refusing the plastic straws also has a high value (4.06). This does not mean that these are equally associated with the ZW lifestyle by the consumers. As the factor analysis revealed, these activities belong at least to two different dimensions of acting against waste production on the consumers' level.

After the factor analysis, a Multiple Linear Regression model was built in order to confirm the predictor value of the three identified factors (Reduce, Reuse and Recycle) on the general ZW lifestyle perception (RQ1). The three ZW dimensions explaining power is $\mathrm{R}^{2}=0.390$, and returned that only the Reduce dimension is a significant predictor at 0.05 level $(\beta=0.583, \mathrm{p}<0.001)$. The Reuse dimension is close to being significant, but actually, it is not $(\beta=0.080, \mathrm{p}=0.088)$, while the Recycle dimension has no effect on the perceived ZW lifestyle $(\beta=0.003, p=0.946)$ (Table 3).

In order to check multicollinearity, the Variance inflation factor (VIF) statistics have been applied. Also, the normality of the standardized residuals was checked. No multicollinearity and normality problems have been identified in the case of the regression models.

After the factors were revealed, for each ZW dimension a Multiple Linear Regression analysis was applied, using as independent variables the social norm vs. individualistic values, the altruistic vs. the egoistic motivation, the attitude towards the zero wasters and the level of activity on different social media platforms (RQ2). 
Table 3

\section{Determinants of the ZW lifestyle adoption}

\begin{tabular}{|l|l|c|c|c|c|c|}
\hline \multicolumn{1}{|c|}{ Model } & & B & Std. Error & Beta & t & Sig. \\
\hline Dependent & (Constant) & 1.147 & 0.188 & & 6.115 & 0.000 \\
\cline { 2 - 7 } $\begin{array}{l}\text { Variable: } \\
\text { ZW life adopt } \\
\text { Adjusted R }=0.390\end{array}$ & REDUCE & 0.663 & 0.057 & 0.583 & 11.630 & 0.000 \\
\cline { 2 - 7 } & REUSE & 0.081 & 0.047 & 0.080 & 1.710 & 0.088 \\
\cline { 2 - 7 } & RECYCLE & 0.002 & 0.036 & 0.003 & 0.067 & 0.946 \\
\hline
\end{tabular}

In the case of Reducing dimension six out of seven covariates were found to be significant. Conforming to the mainstream's norm (SN) has a negative impact on reducing adoption $(\beta=-0.154, \mathrm{p}<0.001)$, while personal norm, meaning following the own principles and values, influences positively the reducing adoption $(\beta=0.129, \mathrm{p}=0.002)$. Altruistic motivation is the second strongest predictor of Reducing behavior $(\beta=0.283$, $\mathrm{p}<0.001$ ), while the egoistic motivation does not have an impact on waste reduction initiatives. The attitude towards the zero wasters influences positively the waste reduction $(\beta=0.130, p=0.003)$. Both YouTube watching frequency and Facebook group activity have a positive impact on reducing behavior. Moreover, the Facebook group activity is the strongest predictor of reducing behavior $(\beta=0.330, \mathrm{p}<0.001)$. These variables all together explain $\mathrm{R}^{2}=41.5 \%$ of the variation in the dependent variable (Table 4 ).

Table 4

Determinants of the ZW lifestyle dimensions

\begin{tabular}{|l|l|c|c|c|c|c|}
\hline \multicolumn{1}{|c|}{ Model } & & B & Std. Err. & Beta & t & Sig. \\
\hline Dependent & Venstant) & -0.217 & 0.394 & & -0.550 & 0.583 \\
\cline { 2 - 7 } $\begin{array}{l}\text { Variable: } \\
\text { REDUCE } \\
\text { Adjusted } \\
\text { R2=0.404 }\end{array}$ & SN & -0.143 & 0.038 & -0.154 & -3.746 & 0.000 \\
\cline { 2 - 7 } & PN & 0.136 & 0.043 & 0.129 & 3.154 & 0.002 \\
\cline { 2 - 7 } & ALTRmot & 0.409 & 0.065 & 0.283 & 6.333 & 0.000 \\
\cline { 2 - 7 } & EGOmot & -0.004 & 0.040 & -0.005 & -0.110 & 0.912 \\
\cline { 2 - 7 } & ZWatt & 0.212 & 0.071 & 0.130 & 2.999 & 0.003 \\
\cline { 2 - 7 } & ZW YT watching & 0.147 & 0.049 & 0.125 & 2.975 & 0.003 \\
\cline { 2 - 7 } & ZW FB activity & 0.358 & 0.047 & 0.330 & 7.619 & 0.000 \\
\hline \multirow{2}{*}{$\begin{array}{l}\text { Vependent } \\
\text { REUSE } \\
\text { Adjusted }\end{array}$} & Constant) & 0.988 & 0.528 & & 1.871 & 0.062 \\
\cline { 2 - 7 } R2=0.164 & SN & -0.154 & 0.051 & -0.146 & -3.005 & 0.003 \\
\cline { 2 - 7 } & PN & 0.184 & 0.058 & 0.153 & 3.167 & 0.002 \\
\cline { 2 - 7 } & ALTRmot & 0.231 & 0.087 & 0.141 & 2.673 & 0.008 \\
\cline { 2 - 7 } & EGOmot & 0.022 & 0.053 & 0.022 & 0.418 & 0.676 \\
\cline { 2 - 7 } & ZWatt & -0.018 & 0.095 & -0.010 & -0.191 & 0.848 \\
\cline { 2 - 7 } & ZW YT watching & 0.181 & 0.066 & 0.136 & 2.740 & 0.006 \\
\cline { 2 - 7 } & ZW FB activity & 0.245 & 0.063 & 0.199 & 3.885 & 0.000 \\
\hline
\end{tabular}

Continued on the next page 
Regional and Business Studies Vol 11 No 2

Continued from the page before

\begin{tabular}{|l|l|c|c|c|c|c|}
\hline Dependent & Constant) & 0.832 & 0.702 & & 1.186 & 0.236 \\
\cline { 2 - 7 } Variable: \\
RECYCLE & SN & -0.231 & 0.068 & -0.168 & -3.405 & 0.001 \\
\cline { 2 - 7 } Adjusted & PN & 0.037 & 0.077 & 0.023 & 0.474 & 0.636 \\
\cline { 2 - 7 } $\mathrm{R}^{2}=0.143$ & ALTRmot & 0.399 & 0.115 & 0.186 & 3.469 & 0.001 \\
\cline { 2 - 7 } & EGOmot & 0.080 & 0.071 & 0.059 & 1.130 & 0.259 \\
\cline { 2 - 7 } & ZWatt & 0.057 & 0.126 & 0.024 & 0.454 & 0.650 \\
\cline { 2 - 7 } & ZW YT watching & 0.032 & 0.088 & 0.018 & 0.360 & 0.719 \\
\cline { 2 - 7 } & ZW FB activity & 0.346 & 0.084 & 0.215 & 4.134 & 0.000 \\
\hline
\end{tabular}

For the Reusing and Recycling behavior, the SN remained as a negative predictor for adopting the behavior $(\beta=-0.146, p=0.003 ; \beta=-0.168, p=0.001)$, the ZW Facebook group activity the strongest positive predictor $(\beta=0.199, \mathrm{p}<0.001$; $\beta=0.215, p<0.001)$, and the ALTRmot also a strong positive covariate of these behaviors $(\beta=0.141, p=0.008 ; \beta=0.186, p=0.001)$. In the case of Recycling behavior, no other variable has been found significant. In the case of Reusing behavior the PN guidance $(\beta=0.153, p=0.002)$ and the ZW YT watching $(\beta=0.136$, $\mathrm{p}=0.006)$ have also a positive impact (Table 4).

\section{CONCLUSIONS}

The aim of the study was to outline the behavioral dimensions of the zero waste lifestyle on the consumer level and to identify the predictors of this behavior. According to our results, reducing waste is considered by consumers as the main dimension of the ZW lifestyle. In a ZW system and a 3R hierarchy, reducing waste is also considered to be the main priority (Lehmann, 2011a). This result could be explained by the fact that it is the easiest to apply in everyday life if we take a closer look at the involved items. Having their own shopping bag, textile bags for patisseries or for vegetables, an own water bottle and food box, refusing plastic straw and other disposable eating paraphernalia could be managed independently from the others, on the household level of each consumer. These individually performable efforts are seen by the respondents as the main components of the ZW lifestyle. The acquisition of reused products and items require some infrastructure on the supply side to be adopted by consumers. Recycling activities also need specific infrastructure. Despite the fact that the selective garbage collecting gained high individual score, meaning that it is widely adopted behavior, it is not seen by the respondents as a ZW lifestyle component. Thus, ZW lifestyle is something more personal in the eyes of those who practice it, shaped by the individual effort of each.

Regarding the determinants of the ZW lifestyle, we have found some insightful results. The zero wasters are individualistic people, they follow their own principles, and they are nonconformists towards the mainstream's lifestyle. They are guided by altruistic motivations and have a positive attitude towards people who are living ZW. Contrarily to other studies that found a positive impact or no impact of 
subjective norms on certain ZW activities, the present study found a significant negative impact of following the behavior of people around consumers. This means that the ZW adoption is sabotaged by the conformity to the generally adopted lifestyle. When the number of followers of the ZW principles reaches the critical mass, probably this barrier will disappear. There are already signs of embracing ecofriendly ideas not only by niche suppliers but also by conventional companies (Angus and Westbrook, 2019). In order to ZW go mainstream, social media platforms are important vehicles for ZW messages. Those consumers, who are more committed to ZW lifestyle, are more active in social media either as followers or as posters - a phenomenon already signalled by previous studies (Fuenteset al., 2019).

As a limitation of our study it should be mentioned that the sample was not representative of the population as the women respondents were heavily overrepresented. However, in several environmentally conscious behavior studies it has been found that women with high education levels and from the urban areas are more willing to employ green behavior (Straughan and Roberts, 1999). Another limitation, and also a suggestion for further research, is to test the ZW dimension scale before analyzing other covariates. This scale creation and refining process offer valuable and unexplored opportunities for further research. Also, other covariates can be included in this study to outline better the ZW adoption behavior patterns. In several studies, the perceived behavioral control or convenience issues (Liobikiene et al., 2016; White et al., 2019) are found to be important predictors of the environmentally friendly behavior.

The ZW concept on the consumer level still seems to be a bottom-up movement, which, for example, is not associated with the already widely adopted recycling activities. In order to benefit from the social and economic opportunities offered by pro-environmental consumer movements, the investigation of the ZW consumer lifestyle remains a promising research topic.

\section{REFERENCES}

Ajzen, I. (1991): The Theory of Planned Behavior. In: Organization Behavior and Human Decision Processes, 50. 2. 179-221 p.

Angus, A., Westbrook. G. (2019): Top 10 Global Consumer Trends 2019. [online] <URL: https://go.euromonitor.com/white-paper-EC-2019-Top-10-GlobalConsumer-Trends.html>

Bedard, S.A.N., Tolmie, C.R. (2018): Millennials' Green Consumption Behaviour: Exploring the Role of Social Media. In: Corporate Social Responsibility and Environmental Management, 25. 6. 1388-1396 p. doi: 10.1002/csr.1654

Davies, J, Foxall, G. R., Pallister, J. (2002): An Integrated Model of Recycling. In: Marketing Theory, 2. 1. 29-113 p. doi: $10.1177 / 1470593102002001645$

European Commission (2014): Towards a Circular Economy: A Zero Waste Programme for Europe. [online] <URL:

https://ec.europa.eu/environment/circular-economy/pdf/circular-economycommunication.pdf $>$ 
European Parliament and Council (2008): Directive 2008/98/EC of the European Parliament And of the Council of 19 November 2008 on Waste and Repealing Certain Directives. In: Official Journal of the European Union. [online] <URL: https:/ / eur-lex.europa.eu/legalcontent/EN/TXT/PDF/?uri=CELEX:32008L0098\&from=EN>

Fishbein, M., Ajzen, I. (1975): Belief, Attitude, Intention, and Behavior: An Introduction to Theory and Research. Boston: Addison-Wesley, 578 p. ISBN13: 978-0201020892

Fuentes, C., Enarsson, P., Kristoffersson, L. (2019): Unpacking package free shopping: Alternative retailing and the reinvention of the practice of shopping. In: Journal of Retailing and Consumer Services, 50. 258-265. p. doi: 10.1016/j.jretconser.2019.05.016

Graham-Rowe, E., Jessop, D.C., Sparks, P. (2014): Identifying motivations and barriers to minimising household food waste. In: Resources, Conservation and Recycling, 84. 15-23. p. doi: 10.1016/j.resconrec.2013.12.005

Hannon, J., Zaman, A. (2018): Exploring the Phenomenon of Zero Waste and Future Cities. In: Urban Science, 2. 3. 90. p. doi: 10.3390/urbansci2030090

Izagirre-Olaizola, J., Fernández-Sainz, A., Vicente-Molina, M.A. (2014): Internal determinants of recycling behaviour by university students: a cross-country comparative analysis. In: International Journal of Consumer Studies, 39. 1. 2534. p. doi: $10.1111 /$ ijcs. 12147

Khan, F., Ahmed, W., Najmi, A. (2019): Understanding consumers' behavior intentions towards dealing with the plastic waste: Perspective of a developing country. In: Resources, Conservation and Recycling, 142. 49-58. p. doi: 10.1016/j.resconrec.2018.11.020

Kirchherr, J., Reike, D., Hekkert, M. (2017): Conceptualizing the circular economy: An analysis of 114 definitions. In: Resources, Conservation and Recycling, 127. 221-232. p. doi: 10.1016/j.resconrec.2017.09.005

Laroche, M., Bergeron, J., Barbaro-Forleo, G. (2001): Targeting consumers who are willing to pay more for environmentally friendly products. In: Journal of Consumer Marketing, 18. 6. 503-520. p. doi: 10.1108/eum0000000006155

Lehmann, S. (2011a): Optimizing Urban Material Flows and Waste Streams in Urban Development through Principles of Zero Waste and Sustainable Consumption. In: Sustainability, 3. 1. 155-83. p. doi: 10.3390/su3010155

Lehmann, S. (2011b.): Resource Recovery and Materials Flow in the City: Zero Waste and Sustainable Consumption as Paradigms in Urban Development. In: Sustainable Developement Law \& Policy, 11. 1. 28-68 p.

Li, D., Zhao, L., Ma, S., Shao, S., Zhang, L. (2019): What influences an individual's pro-environmental behavior? A literature review. In: Resources, Conservation and Recycling, 146. 28-34. p. doi: 10.1016/j.resconrec.2019.03.024

Liobikienè, G., Mandravickaite, J., Bernatoniené, J. (2016): Theory of planned behavior approach to understand the green purchasing behavior in the EU: A cross-cultural study. In: Ecological Economics, 125. 38-46. p. doi: 10.1016/j.ecolecon.2016.02.008 
Ma, J., Hipel, K.W., Hanson, M.L., Cai, X., Liu, Y. (2018): An analysis of influencing factors on municipal solid waste source-separated collection behavior in Guilin, China by Using the Theory of Planned Behavior. In: Sustainable Cities and Society, 37. 336-343. p. doi: 10.1016/j.scs.2017.11.037

McDougle, L.M., Greenspan, I., Handy, F. (2011): Generation Green: Understanding the Motivations and Mechanisms Influencing Young Adults' Environmental Volunteering. In: International Journal of Nonprofit and Voluntary Sector Marketing, 341. 325-341 p. doi: 10.1002/nvsm.431

Minelgaitè, A., Liobikienè, G. (2019): Waste problem in European Union and its influence on waste management behaviours. In: Science of The Total Environment, 667. 86-93. p. doi: 10.1016/j.scitotenv.2019.02.313

Kaplan Mintz, K., Henn, L., Park, J., Kurman, J. (2019): What predicts household waste management behaviors? Culture and type of behavior as moderators. In: Resources, Conservation and Recycling, 145. 11-18. p. doi: 10.1016/j.resconrec. 2019.01.045

Moisander, J., (2007): Motivational complexity of green consumerism. International Journal of Consumer Studies, 31. 4. 404-409. p. doi: 10.1111/j.14706431.2007.00586.x

Onel, N., Mukherjee, A. (2017): Why do consumers recycle? A holistic perspective encompassing moral considerations, affective responses, and self-interest motives. In: Psychology \& Marketing, 34. 10. 956-971. p. doi: 10.1002/mar.21035

Pandey, R.U., Surjan, A., Kapshe, M. (2018): Exploring linkages between sustainable consumption and prevailing green practices in reuse and recycling of household waste: Case of Bhopal city in India. In: Journal of Cleaner Production, 173. 49-59. p. doi: 10.1016/j.jclepro.2017.03.227

Pietzsch, N., Ribeiro, J.L.D., de Medeiros, J.F. (2017): Benefits, challenges and critical factors of success for Zero Waste: A systematic literature review. In: Waste Management, 67. 324-353. p. doi: 10.1016/j.wasman.2017.05.004

Planet Aid (2016): What Is the Zero-Waste Movement? [online] <URL https://www.planetaid.org/blog/what-is-the-zero-waste-movement>

Prendeville, S., Sanders, C., Sherry, J., Costa, F. (2014): Circular Economy: Is it enough?. EcoDesign Centre: Wales, UK. [online] <URL: https://pdfs.semanticscholar.org/943c/814c3300b69a06bd411d2704ec3baa3a 0892.pdf>

Roberts, J.A., Bacon, D.R. (1997): Exploring the Subtle Relationships between Environmental Concern and Ecologically Conscious Consumer Behavior. In: Journal of Business Research, 40. 1. 79-89. p. doi: 10.1016/s01482963(96)00280-9

Sajtos, L., Mitev, A. (2007): SPSS kutatási és adatelemzési kézikönyv (in Hung.). Budapest: Alinea Kiadó. 402. p. ISBN: 978-963-9659-08-7

Straughan, R.D., Roberts, J.A. (1999): Environmental segmentation alternatives: a look at green consumer behavior in the new millennium. In: Journal of Consumer Marketing, 16. 6. 558-575. p. doi: 10.1108/07363769910297506 
Taber, K.S. (2017): The Use of Cronbach's Alpha When Developing and Reporting Research Instruments in Science Education. In: Research in Science Education, 48. 6. 1273-1296. p. doi: 10.1007/s11165-016-9602-2

Thygersen, J. (1999): The Ethical Consumer. Moral Norms and Packaging Choice. In: Journal of Consumer Policy, 22. 4. 439-460. p. doi: 10.1023/a:1006225711603

Vaske, J.J., Beaman, J., Sponarski, C.C. (2017): Rethinking Internal Consistency in Cronbach's Alpha. In: Leisure Sciences, 39. 163-173 p. doi: 10.1080/01490400.2015.1127189

Weber, S., Lynes, J., Young, S. B. (2016): Fashion interest as a driver for consumer textile waste management: reuse, recycle or disposal. In: International Journal of Consumer Studies, 41. 2. 207-215. p. doi: 10.1111/ijcs.12328

Webster, Jr., F.E. (1975): Determining the Characteristics of the Socially Conscious Consumer. Journal of Consumer Research, 2. 3. 188-196. p. doi: 10.1086/ 208631

White, K., Habib, R., Hardisty, D.J. (2019): How to SHIFT Consumer Behaviors to be More Sustainable: A Literature Review and Guiding Framework. In: Journal of Marketing, 83. 3. 22-49.p. doi: 10.1177/0022242919825649

Zaman, A.U. (2015): A comprehensive review of the development of zero waste management: lessons learned and guidelines. In: Journal of Cleaner Production, 91. 12-25. p. doi: 10.1016/j.jclepro.2014.12.013

Zaman, A.U. (2016): A comprehensive study of the environmental and economic benefits of resource recovery from global waste management systems. In: Journal of Cleaner Production, 124. 41-50. p. doi: 10.1016/j.jclepro.2016.02.086

Zero Waste Europe (2019): The Zero Waste Lifestyle. [online] <URL: https://zerowasteeurope.eu/zero-waste-in-lifestyle/>

Zimmer, M.R., Stafford, T.F., Stafford, M.R. (1994): Green issues: Dimensions of environmental concern. In: Journal of Business Research, 30. 1. 63-74. p. doi: 10.1016/0148-2963(94)90069-8

ZWIA (Zero Waste International Alliance)(2018): Zero Waste Definition. [online] <URL: http://zwia.org/zero-waste-definition/>

Correspondent author:

\section{Zsuzsa SĂPLĂCAN}

Babeş-Bolyai University

Faculty of Economics and Business Administration

RO-400084, Cluj-Napoca, Str. Mihail Kogălniceanu, nr. 1

e-mail: zsuzsa.pal@econ.ubbcluj.ro 